\title{
The Present and Future of Positive Technologies
}

\author{
Cristina Botella, Ph.D., ${ }^{1,2,3}$ Giuseppe Riva, Ph.D., ${ }^{4,5}$ Andrea Gaggioli, Ph.D.,, ${ }^{4,5}$ \\ Brenda K. Wiederhold, Ph.D., M.B.A., BClA, ${ }^{6,7}$ Mariano Alcaniz, Ph.D., ${ }^{3-8}$ and Rosa M. Baños, Ph.D. ${ }^{2,3}$
}

\begin{abstract}
The goal of this work is to delimit the field of Positive Technology—the scientific and applied approach to the use of technology for improving the quality of our personal experience. This new field combines the objectives of Positive Psychology with enhancements of Information and Communication Technologies (ICTs) by focusing on three key variables-emotional quality, engagement/actualization, and connectedness-that are able to transform our personal experience in a tool for building new and enduring personal resources. In fact, Positive Technologies include those designed to manipulate the quality of experience through its structuring, augmentation and/or replacement, with the goal of increasing wellness, and generating strengths and resilience in individuals, organizations, and society. This work describes existing Positive Technologies, classified according to their objectives: hedonic (mood-altering devices, which use ICTs to induce positive and pleasant experiences); eudaimonic (systems designed to support individuals in reaching engaging and self-actualizing experiences); and social/interpersonal (technologies that seek to improve the connectedness between individuals, groups, and organizations). Finally, possible directions of future developments are suggested.
\end{abstract}

\section{Introduction}

$\mathbf{P}$ Ositive Technology (PT) could Be Defined as the scientific and applied approach for improving the quality of our personal experience with the goal of increasing wellness, and generating strengths and resilience in individuals, organizations, and society. In this volume, ${ }^{1}$ we used the Positive Psychology (PP) framework to suggest the use of technology to enhance three specific features of our experienceemotions, engagement, and connectedness-that serve to promote adaptive behaviors and positive functioning. According to Seligman ${ }^{2}$ and Csikszentmihalyi, ${ }^{3}$ PP investigates human potential, virtues, and their effects, and promotes exploring topics such as optimism, love, perseverance, and originality: it is the scientific study of what makes people feel "happy" and "well." Applications and interventions in this field focus on identifying people's strengths and building resilience, engagement, and meaning. Herein, we consider how PP's objectives mesh with the power of certain new technologies, specifically the latest Information and Communications Technologies (ICTs; not presently including such technologies related to biotechnology).
The use of tools have facilitated human progress, ${ }^{4}$ from the first "Oldwoman stone tools," the Internet, Google, and YouTube, as well as the powerful social Facebook and Twitter networks. The question arises whether all these tools should be considered "positive" technologies. The answer is that they should not. First, technology itself is neutral. Humans have developed thousands of tools, but they also include "negative" ones, such as weapons to control territories and other people. Second, to be labeled as PTs, technologies should be designed to improve the quality of the personal experience, which in turn serves to promote wellness and generate resources and strengths in individuals. Third, we suggest that the main tools to achieve this goal are the structuring, augmentation, and replacement potential offered by ICTs: multimedia computing, virtual reality (VR), and the Internet.

The aim of this paper is to delimit the PT field of study, define inclusion criteria, conduct an initial review on which PTs would be included, and suggest possible directions of future developments. Figure 1 shows a graphic summary of the levels of "positive human functioning" using ICT's tools and Positive Psychology goals.

${ }^{1}$ Dpto. Psicología Básica, Clínica y Psicobiología, Universitat Jaume I, Castellón, Spain.

${ }^{2}$ Dpto. Personalidad, Evaluación y Tratamientos Psicológicos, Universitat de València, Valencia, Spain.

${ }^{3}$ CIBER Fisiopatología Obesidad y Nutrición (CB06/03), Instituto de Salud Carlos III, Madrid, Spain.

${ }^{4}$ Interactive Communication and Ergonomics of NEw Technologies-ICE-NET Lab., Università Cattolica del Sacro Cuore, Milan, Italy.

${ }^{5}$ Applied Technology for Neuro-Psychology Lab.-ATN-P Lab., Istituto Auxologico Italiano, Milan, Italy.

${ }^{6}$ Virtual Reality Medical Institute, Brussels, Belgium.

${ }^{7}$ Virtual Reality Medical Center, San Diego, California.

${ }^{8}$ Universidad Politécnica de Valencia, Valencia, Spain. 


\section{Positive Technology}

The scientific and applied approach to the use of technology for improving the quality of our personal experience through its structuring, augmentation and/or replacement

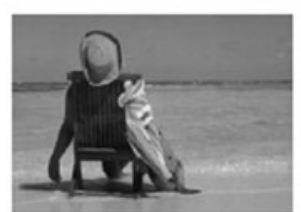

Hedonic level

Using technology to induce positive and pleasant experiences

(THE ENJOYING SELF)

\section{OBJECTIVES}

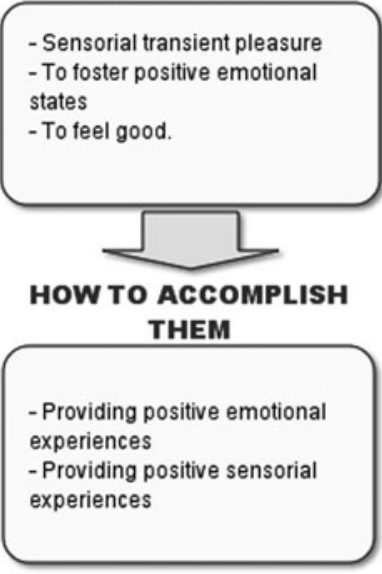

EXAMPLES

- To enjoy positive transient experiences

- To enjoy listening to music

- To relax
- To enjoy sensorial pleasures

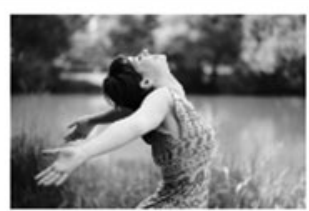

\section{Eudaimonic level}

Using technology to support individuals in reaching experiences

(THE GROWING SELF)

OBJECTIVES

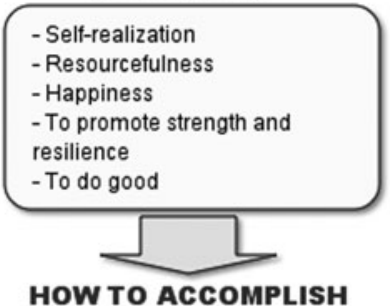

HOW TO ACCOMPLISH THEM

\section{- Systematic positive mood \\ induction training \\ -Well-being training \\ - Reminiscence training \\ - Life theme training \\ - Setting significant goals}

\section{EXAMPLES}

- Flow experiences

- Self empowerment

- Self growing engaging and self-actualizing

\section{Transition Technologies}

Some ICTs have been used to improve the application of psychological treatments, and in this sense, they are aimed to promote psychological wellness. The potential and utility of the ICTs for psychological treatments been demonstrated in at least the following technological areas: computer-assisted therapy, VR techniques, and using the Internet and its evolution-Web 2.0-as treatment support mechanisms.

\section{Computer-aided therapy}

This includes computerized systems designed to aid psychological treatments. This approach is not new. ${ }^{6}$ Initial programs in the late 1970s used computers to increase people's consciousness of their eating habits. ${ }^{7}$ Marks has defended these strategies' usefulness, ${ }^{8-10}$ and the National Institute of Clinical Excellence supports the use of selfapplied programs such as "Beating the Blues" for treating depression and anxiety ${ }^{11,12}$ and "FearFighter" for treating phobias and panic disorders. ${ }^{13}$ Another example is Craske's work, ${ }^{14,15}$ aimed to develop flexible protocols that help treat to them.

\section{Virtual reality}

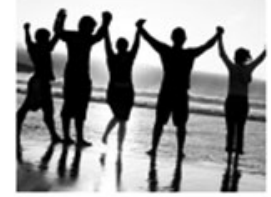

\section{Social \&} Interpersonal level Using technology to support and improve social integration and connectedness (THE SHARED SELF)

\section{OBJECTIVES}

- Facilitation of participatory information sharing

- User-generated contents

- To care for others

- To grow in community life

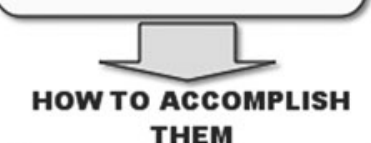

- Creating shared positive

emotional experiences

-Well-being training

- Developing and sharing

strengths

- Setting shared significant goals

\section{EXAMPLES}

- Wikipedia

- YouTube

- Social networks

- Networked Flow (shared flow

experiences)
FIG. 1. Positive Technology: Levels of positive human functioning using ICT's tools and Positive Psychology goals.

different problems, such as the CALM study. In general, computer-aided therapy uses technology to structure the patients' experience by providing goals, rules, and feedback

Various recent randomized controlled studies have demonstrated the effectiveness of VR for psychological treatments. Results obtained in the review studies ${ }^{16-20}$ and meta-analysis studies ${ }^{21}$ show that they are effective alternative treatments, which even have clear advantages over in vivo exposure: VR can be applied in therapists' offices, and successive controlled sessions allow patients to face their fears in a very controlled, systematic way by creating a personalized exposure hierarchy. Virtual environments are an appropriate interim step for those too afraid to begin in vivo exposure. Furthermore, virtual environments were also found to be useful for chronic pain conditions ${ }^{22,23}$ and eating disorders. ${ }^{24}$ Data regarding the efficacy of variants of this technology, such as augmented reality procedures for the 
treatment of phobias, have also been documented. ${ }^{25,26}$ In sum, VR uses technology to replace the patients' original experience with a different one fully controllable by the therapist. Moreover, it can be structured, too, to provide specific goals, rules, and feedback.

\section{The Internet}

A new method of delivering psychological treatment merges cognitive behavior therapy with the Internet. ${ }^{27}$ In these approaches, patients typically work through a self-help guide adapted for the Internet, and can use this guide as needed at their own pace. Such programs, focused on selfhelp interventions, are examples of affordable and effective interventions for anxiety disorders. ${ }^{28}$ A fundamental advantage of Internet-based programs is that they can reduce contact time between patients and therapists, thereby lowering costs and even allowing patients located far from a therapist to receive treatment. These approaches are helping disseminate evidence-based treatments to a larger percentage of the population. ${ }^{29}$ Recent systematic reviews of Internet-based treatments show that they are effective and useful from a cost-benefit perspective..$^{20,27}$

\section{Web 2.0 and Social Networks}

A final emerging trend is the use of Web 2.0 technologies and/or semantic Web approaches to enable and facilitate specifically (a) social networking, (b) participation, (c) apomediation, (d) openness, and (e) collaboration. ${ }^{30}$ The emergence of social networking platforms create new levels of patient participation, as well as unprecedented opportunities for both engaging patients and connecting them with informal and formal caregivers, health professionals, and researchers.

In summary, all the online technologies allow an augmentation of the experience of the patients, both by permitting them to overcome the time and place constrains of our face-to-face experience, and by offering them an enriched multimedia experience. Here, again, it is possible to structure the characteristics of the experience by providing goals, rules, and feedback.

Because these ICT-based applications have substantially improved the psychological treatment field, should they be considered PTs? The answer is that they should not. Although they show that it is possible to use technology to modify our personal experience, they have been conceived from a classical Clinical Psychology approach in that they intend to "fix what has been damaged" or "treat problems." They have not been designed to manipulate the quality of experience for promoting and fostering the positive aspects of human functioning, as PTs must.

\section{Positive Technologies}

So far, very few applications exist that can be included within the PT conceptual framework, namely those that manipulate the quality of experience to create wellbeing, strength, and resilience. Therefore, herein, we analyze the developments made thus far, using the outline set forth by Riva et al. ${ }^{1}$ in this same volume.

There are many ways to classify technologies, depending on the different dimensions or characteristics of the gadgets used, the contexts where they are used, and so on. In this article, we would like to classify PTs trying to follow the theoretical guidelines proposed by the PP, which, when organizing the field of study of the human well-being, remark that traditionally there have been different approaches: one centered on the ephemeral well-being (hedonism), and another more centered on the search of a full and meaningful life (eudaiomonia). Also, PP, when establishing its field of study, remarks that its objective is not only individuals, but also groups, societies, and organizations. That is why we add a third category to the PTs, which refers to this social dimension of the search and study of well-being.

\section{Hedonic level: The enjoying self}

As seen in Figure 1, the feeling of hedonism or sensorial pleasure is associated with situations in which people feel excited, relaxed, happy, and far away from anything worrisome. These positive emotional states, such as joy, relaxation, or savoring, may be considered as the initial steps of the Hierarchy of Needs model developed by Maslow. ${ }^{31}$ Inducing such positive emotional states can be very useful from a treatment perspective; ${ }^{32-34}$ hence, certain technological applications are designed to help users achieve a positive emotional state and wellness in the short term.

Some studies have already explored this area. Mood devices were developed for the EMMA Project (Engaging Media for Mental Health Applications) called Emotional Parks, which combine Mood Induction Procedures (MIPs) with VR to induce positive emotions (happiness and relaxation). ${ }^{35-37}$ MIPs are experimental procedures designed to provoke transitional mood states in non-natural situations in a controlled manner. ${ }^{38}$ Emotional Parks include the following MIPs: Velten's self-statements; ${ }^{39}$ affective images from IAPS; ${ }^{40}$ music to induce happy or relaxed mood states; and pictures or videos. MIPs are integrated within a virtual park, all of whose elements were designed to induce happiness and relaxation. Botella et al. ${ }^{41}$ developed another mood device that uses VR and other ICTs, called the Butler System. The Butler System is an e-health platform designed to improve the elderly population's quality of life. One of its applications is a VR environment that represents a walk through nature, and also contains a series of MIPs. It includes a narrative that invites participants to stroll through a wide, green field where they can enjoy a beautiful day in a lively and colorful field or in peaceful and relaxing context. Participants also can practice different emotional training procedures: slow breathing rhythms, attentional and mindfulness strategies, reminiscence, and so on.

These applications have been tested and have demonstrated an ability to induce positive mood states in users, and to foster positive affect and diminish negative affect, not only for individuals who were already emotionally balanced, but also for those who presented high sadness levels due to a prior experimental sadness induction. ${ }^{41}$ The Butler system's MIP has been shown to improve mood states of elderly users: after using the system, their positive emotions increased and negative ones decreased. ${ }^{37,41}$

Riva's team ${ }^{42}$ developed a mood device using VR called Relaxation Island, which uses interactive digital media and an environment designed to alter participants' psychological states. Relaxation Island's aim is to support established 
relaxation techniques as part of interventions for specific anxieties such as examination stress; it is also simply a virtual destination for relaxation. Furthermore, VR environments developed by Wiederhold's team are being used in Iraq, Afghanistan, and U.S. military facilities to help military members generate general relaxation states. ${ }^{43}$

PTs' ability to create positive experiences in a controlled way is a significant issue. Some theorists have argued that positive emotions are markers of well-being or that they trigger approach behavior. Furthermore, although from a PP perspective hedonic enjoyment would fall within the first two steps of Maslow's hierarchy ${ }^{31}$ and positive emotional states are only momentary, their benefits last in the form of traits, social bonds, and abilities that endure into the future. In this sense, positive emotions can lay the foundations for Fredrickson's " "broaden and build" process. According to this theory, positive emotions were important to survival as they expand cognition and behavioral tendencies. Positive emotions increase the number of potential behavioral options, and the expanded cognitive flexibility evident during positive emotional states results in resource building that becomes useful over time. According to Fredrickson, the development and cultivation of positive emotions will help people lead full lives, and these PTs at the hedonic level could have inherent value to human growth.

\section{Eudaimonic level: The growing-self or self-empowerment}

Current theories about happiness attribute eudaimonic ideas to the Aristotelian tradition, which urges people to live according to their ideals or perfection criteria that give life a meaning. Such efforts will result in an optimum state, the eudaimonic condition, as captured in Figure 1. Humanistic and existential psychologists (e.g., Rogers, Maslow, and Erikson) have given this state different names: motivation or self-realization.

One way PTs can be used to stimulate eudaimonia is by using it in a repetitive and systematic way, with a given objective, $^{32,45}$ as the PT applications previously described do. Specific training procedures could be developed to encourage setting long-term goals with ambitious change objectives. According to Fredrickson, ${ }^{32}$ these strategies can facilitate personal growth, and they can help gain resources, which may be physical (e.g., sleep quality, immunity from illnesses and diseases), social (e.g., expanded social connections, social support), psychological (e.g., trait resilience, optimism), or intellectual (e.g., creativity, mindfulness). Moreover, such systematic training can course-correct the genetic predisposition of one's emotional life, or happiness "set-point." 46 We are conducting research in this area, by inducing a happy state in subclinical participants three times a week, and observing the effect this systematic training has. ${ }^{47}$

Other types of interventions have the objective of achieving the eudaimonic level. For example, well-being training is a strategy for increasing psychological well-being and resilience. ${ }^{48,49}$ Findings indicate that a sense of flourishing and resilience can be promoted by interventions leading to a positive evaluation of one's self, a sense of continued growth, the belief that life is meaningful, healthy relationships, the capacity to manage one's life effectively, and a sense of self- determination. The focus of well-being training follows Ryff's conceptual framework. ${ }^{50}$ The goal is to help people to reach an optimum level in the dimensions of psychological wellbeing: environmental mastery, personal growth, purpose in life, autonomy, self-acceptance, and positive relations with others. ${ }^{51}$ In fact, the data show that resilience and well-being can be promoted by interventions leading to a positive evaluation of one's self, a sense of continued growth and development, the belief that life is purposeful and meaningful, the possession of quality relations with others, the capacity to manage effectively one's life, and a sense of self-determination. ${ }^{49}$ For this purpose, and following this rationale, we developed an application called EARTH (Emotional Activities Related to Health) within the framework of the MARS500 research project (www.esa.int/esaMI/Mars500/). It is designed to help astronauts in a future mission to Mars. The MARS500 project simulates this space trip and studies the psychological effects of a 520-day confinement of a group of six people in a limited space. Our group is hereby analyzing the usefulness of PTs. The EARTH system includes the VR's MIPs previously described and an application called the Book of Life, which includes several chapters that focus on significant events of one's life experiences and also one's future plans. Each chapter is designed to promote specific psychological strengths. Users are offered various audiovisual media in the system: images, videos, music, texts, and, whenever possible, personalized elements. Once the users' memories and plans have been structured and analyzed, users can recall and enjoy them at any time. Because the MARS500 experiment is currently in progress, data are not available yet. Within this same line, we are using these tools to promote positive emotions and psychological strengths in people receiving cancer treatment. The objective is working with the Book of Life and the mood induction tools in order to promote growing resources in people going through negative vital circumstances. At this very moment, we are at the carrying out phase of this study.

As for resiliency, Wiederhold \& Wiederhold have been working with elite individuals (including elite athletes and elite medical and military personnel) in order to enhance and strengthen their already strong skill sets. ${ }^{52}$ Since the late 1990s, they have been teaching them mental skills for "fortressing" their ability to withstand future stressors.

From the previously mentioned Ryff's dimensions, it is important to remark that a relevant factor in the eudaimonic level is the social network, that is, positive relations with others. Ryff ${ }^{50,51}$ claims eudaimonia is a combination of personal growth, environmental mastery, sense of purpose, autonomy, self-acceptance, and positive relations with others. With regard to this last point, we would like to highlight how important it is for everyone to have warm and trusting relationships with others; to be concerned about the welfare of others; to be capable of strong empathy, affection, and intimacy; and finally, to understand the give-and-take of human relationships. In this line would be the PTs of the next level.

\section{The social and interpersonal level}

Those PTs mainly centered in the promotion of social relationships and in the collaborative and participatory growth would be included here. From an ICT point of view, these social and interpersonal issues can be improved through PTs 
such as the Internet and social networks (not to mention the different connection methods facilitated by all mobile devices). In a way, the connections between millions of people via social networks on the Internet constitute a new and powerful "net-shared-self." We propose this concept in a similar line put forward by Hermans ${ }^{53,54}$ in his "dialogical self" theory, that is, seeing the modern society as a multiplicity of collective voices, any of which may interact with the others in a dialogical fashion. The self transcends the limits of individualism and rationalism. Part of our personal identity influences this new self and, in turn, the contributions of millions of people "connected" shape and influence in our own personal identity. As in the "global village" of the Internet, future ICTs will have to make use of social networks, which will entail interaction between millions of people who do not know each other but who have a determining influence on each other. Nowadays, we are witnessing the way social networks are having such a great influence on social, political, economic, and so on movements. However, for now, this is always being done through social networks, whose basic goal within its development has not been the promotion of wellness within groups, societies, or organizations.

There are still few examples of PTs within the "social" category specifically developed within the PP framework. However, we believe this line of work will be especially relevant in the future. Right now, social networks are showing how becoming part of something and sharing significant goals can be a powerful source of personal reward and of sense of social belonging. Also, this feeling of "being-in-theworld-with-others" can be a maintainer element for perseverance in the objectives and goals. Wikipedia is a seminal example. ${ }^{55}$ It is promoted by the Wikimedia Foundation, which has created a family of free-content projects that are built by user contributions. The mission of the Wikimedia Foundation is "to empower and engage people around the world to collect and develop educational content under a free license or in the public domain, and to disseminate it effectively and globally." Because one of the main aspects of PP is the need to improve education, ${ }^{56}$ Wikipedia is a very powerful PT tool. Calefato et al. ${ }^{55}$ proposed redesigning the Wikipedia tutorial following Fogg's ${ }^{57}$ persuasive concept by giving more space to visual and social elements. Since Wikipedia is a persuasive tool that needs to motivate people to collaborate on creating and disseminating free knowledge, then the tutorial redesign would increase its effectiveness as a persuasive technology.

Another PT example is the PosiPost project, $^{58}$ designed from the PP point of view. It includes various applications: Me (Mobile Internet edition) and Be (Bluetooth edition) for the recording and sharing of positive emotions over distance (Me) and with people in proximity (Be). Participants are asked to complete the sentence "Today, I like__" in order to encourage positive postings which are then distributed to other PosiPost users. This is an example of potential future developments: exchanging experiences that promote participation and connectedness.

Within the "interpersonal social" category of the PTs, we could also mention the contributions centered on obtaining systematic information of our own behavior through the new technologies. In fact, such contributions involve overcoming one of the limitations of the classical self-control approaches, ${ }^{59}$ that is, people can obtain a valuable feedback and improve some aspect of their lives using this information. An example of this is the work by Killingsworth and Gilbert, ${ }^{60}$ "Track Your Happiness" (www.trackyourhappiness.org), a project that investigates what makes life worth living. Using this site, people are able to track their happiness and find out what factors are associated with greater happiness. Within this line, we find Seligman's work "Authentic happiness" (www.authentichappiness.sas.upenn.edu) that proves that being able to measure our own strengths and getting feedback on our achievements is a good incentive to progress and develop. Another example is the "Quantified Self" initiative (http:// quantifiedself.com) by Carmichael, Kelly and Wolf. It is a collaboration of users and tool makers who share an interest in self-knowledge through self-tracking. The purpose is to exchange information about personal projects, tools, tips, and lessons learned. Finally, this third level is related to the "R-M-A/A" parts of the acronym PERMA, that is, Seligman's new model for well-being or flourishing: Positive emotions, Engagement, Relationships, Meaning, Accomplishment/ Achievement. ${ }^{61}$ PT can help us to be connected, to share meaningful goals in order to enable our own individual and collective psychological flourishing.

Concepts such as facilitation of participatory information sharing, interoperability and collaboration, virtual community social networking sites, blogs, wikis, folksonomies, infodemiology, captology, and so on are now quite common. However, their possible implications have not been properly analyzed yet. Although, given the space limitations, it is impossible to analyze all these concepts here and take into account their potential implications from the social psychology point of view, we consider future PTs will have to pay attention to all these new developments that allow us interrelate with many other people and exchange knowledge, interests, plans, or goals with them. Here, the contribution of social psychology is going to be essential. We can also hypothesize about the future when any participant in this emerging "net-shared-self" can be completely focused on contributing elements to help other members of the "netshared-self" (other selves he shares part of his identity with); together they can share optimum flow experiences. Crowd-sourcing ${ }^{62}$ and Crowd-funding ${ }^{63}$ are related emerging phenomena: they manifest the power of every person who can access ICTs. The "net-shared-self" is an entity that all people can contribute to and benefit from. It exists without diminishing human brain developments achieved over millennia. ${ }^{64,65}$

\section{The Future}

In their work, Kanis and Brinkman ${ }^{58\left(\mathrm{p}^{127}\right)}$ associated PP with the use of ICTs to achieve positive change, and described the design of PT: "Naturally, most practitioners in the field of HCI [human-computer interaction] aim to give the user a high-quality experience with technology, but designing technology that actually contributes to people's happiness in their everyday lives is a more complex challenge. There is clearly an opportunity to employ technology for positive change, but how this can be achieved is more difficult to determine."

The 21st century represents a new era in which psychology and technology can interact synergistically. Curiously, existing PP manuals do not include a single chapter on the 
important impact ICTs can have in this field. ${ }^{66}$ Furthermore, the recent book Technology and Psychological Well-being, ${ }^{67}$ which explores the relationship between technology and wellness, does not explore what PP can contribute to this field. With this article, we aim to highlight the urgent need to harness the power of both areas of study by focusing on three key variables-emotional quality (hedonic level), engagement/actualization (eudaimonic level), and connectedness (social level) — that are able to transform our personal experience in a tool for building new and enduring personal resources.

It is important to emphasize the importance of developing technological strategies (such as artificial intelligence or augmented reality) that can provide either new enhanced experiences or technological systems also nurtured by artificial intelligence techniques developed by humans. These new mixed ICT tools might evolve into experts in "helping others," with the objective of making our net-shared experience increasingly more competitive, creative, and capable in the task of helping others. Of course, this has significant ethical implications, which will also need to be explored at greater depth.

\section{Acknowledgments}

This work was partially funded by the INTERSTRESS (FP7-247685; www.interstress.eu) and OPTIMI (FP7-JCT2009-4 248544; www.optimiproject.eu) European research funded projects. Generalitat Valenciana, PROMETEO (2008/ 157). Ministerio de Ciencia y Tecnología (PSI2010-17563). CIBER Fisiopatología de la Obesidad y Nutrición is an initiative of ISCIII.

\section{Disclosure Statement}

No competing financial interests exist.

\section{References}

1. Riva G, Baños R, Botella C, et al. Positive technology: Using interactive technologies to promote human positive functioning. Cyberpsychology, Behavior, \& Social Networking 2012; 1:69-77.

2. Seligman MEP. (2002) Authentic happiness: Using the new positive psychology to realize your potential for lasting fulfillment. New York: Free Press.

3. Csikszentmihalyi M. (1998) Finding flow: The psychology of engagement with everyday life. New York: Basic Books.

4. Stringer CB, Andrews P. Genetic and fossil evidence for the origin of modern humans. Science 1988; 239:1263-8.

5. Semaw S, Rogers MJ, Quade J, et al. 2.6-Million-year-old stone tools and associated bones from OGS-6 and OGS-7, Gona, Afar, Ethiopia. Journal of Human Evolution 2003; 45:169-77.

6. Marks IM, Cavanagh K, Gega L. (2007) Hands-on help: Computer-aided psychotherapy. London: Psychology Press.

7. Porter D. (1978) Patient responses to computer counselling. In Orthner FH, ed. Proceedings: The Second Annual Symposium on Computer Applications in Medical Care. Long Beach, CA: IEEE Computer Society, pp. 233-7.

8. Bachofen M, Nakagawa A, Marks IM, et al. Home selfassessment and self-treatment of obsessive compulsive disorder using a manual and a computer-conducted telephone interview: Replication of a US-UK study. Journal of Clinical Psychiatry 1999; 60:545-9.
9. Carr AC, Ghosh A, Marks IM. Computer-supervised exposure treatment for phobias. Canadian Journal of Psychiatry 1988; 33:112-17.

10. Marks IM, Baer L, Greist JH, et al. Home self-assessment and self-treatment of obsessive compulsive disorder using a manual and a computer-conducted telephone interview: Two UK-US studies. British Journal of Psychiatry 1998; 172:406-12.

11. Cavanagh K, Shapiro D. Technological advances in computer treatment. Journal of Clinical Psychology 2004; 60: 239-51.

12. Proudfoot J, Ryden C, Everitt B, et al. Clinical effectiveness of computer-aided cognitive behavioural therapy for anxiety and depression in primary care. British Journal of Psychiatry 2004; 185:56-62.

13. Marks IM, Kenwright M, McDonough M, et al. Saving clinicians' time by delegating routine aspects of therapy to a computer: A randomised controlled trial in phobia/panic disorder. Psychological Medicine 2004; 34:1-10.

14. Craske M, Roy-Byrne P, Stein M, et al. Treatment for anxiety disorders: Efficacy to effectiveness to implementation. Behavior Research \& Therapy 2009; 47:931-7.

15. Sullivan G, Craske MG, Sherbourne C, et al. Design of the Coordinated Anxiety Learning and Management (CALM) study: Innovations in collaborative care for anxiety disorders. General Hospital Psychiatry 2007; 2:379-87.

16. Botella C, Quero S, Baños R, et al. (2004) Virtual reality and psychotherapy. In Riva G, Botella C, Legeron P, et al., eds. Cybertherapy, Internet and virtual reality as assessment and rehabilitation tools for clinical psychology and neuroscience. Amsterdam: IOS Press.

17. Wiederhold BK, Wiederhold MD. (2004) Virtual reality therapy for anxiety disorders: Advances in education and treatment. New York: American Psychological Association Press.

18. Cukor J, Spitalnick J, Difede J, Rizzo A. Rothbaum BO. Emerging treatments for PTSD. Clinical Psychology Review 2009; 29:715-26.

19. Gorini A, Gaggioli A, Vigna C, Riva G. A second life for eHealth: Prospects for the use of 3-D virtual worlds in clinical psychology. Journal of Medical Internet Research 2008; 10:21.

20. Newman MG, Szkodny L, Llera SJ, et al. A review of technology assisted self-help and minimal contact therapies for drug and alcohol abuse and smoking addiction: Is human contact necessary for therapeutic efficacy? Clinical Psychology Review 2011; 3:178-86.

21. Powers MB, Emmelkamp PMG. Virtual reality exposure therapy for anxiety disorders: A meta-analysis. Journal of Anxiety Disorders 2008; 22:561-9.

22. Wiederhold MD, Wiederhold BK. Virtual reality and interactive simulation for pain distraction. Pain Medicine 2007; 8:182-8.

23. Wender R, Hoffman $H$, Hunner $H$, et al. Interactivity influences the magnitude of virtual reality analgesia. Journal of Cybertherapy \& Rehabilitation 2009; 2:21-4.

24. Aime A, Cotton K, Bouchard S. Reactivity to virtual reality immersion in a subclinical sample of women concerned with their weight and shape. Journal of Cybertherapy \& Rehabilitation 2009; 2:115-26.

25. Botella C, Juan C, Baños RM, et al. (2005) Mixing realities? An application of augmented reality for the treatment of cockroaches phobia. CyberPsychology \& Behavior 2005; 8:161-71.

26. Botella C, Bretón-López J, Quero S, et al. Treating cockroach phobia with augmented reality. Behavior Therapy 2010; 41:401-13. 
27. Andersson G. Using the Internet to provide cognitive behaviour therapy. Behaviour Research \& Therapy 2009; 47:175-80.

28. Botella C, Hofmann SG, Moscovitch DA. A self-applied, Internet-based intervention for fear of public speaking. Journal of Clinical Psychology 2004; 60:821-30.

29. Caspar F. Technological developments and applications in clinical psychology and psychotherapy: Summary and outlook. Journal of Clinical Psychology 2004; 60:347-9.

30. Eysenbach G. Medicine 2.0: Social networking, collaboration, participation, apomediation, and openness. Journal of Medical Internet Research 2008; 10:e22.

31. Maslow AH. (1970) Motivation and personality. 2nd ed. New York: Harper and Row.

32. Fredrickson BL. The value of positive emotions. The emerging science of positive psychology is coming to understand why it's good to feel good. American Scientist 2003; 91:330-5.

33. Taylor SE, Brown JD. Illusion and well-being: A social psychological perspective on mental health. Psychological Bulletin 1988; 103:193-210.

34. Taylor SE, Brown JD. Positive illusions and well-being revisited: Separating fact from fiction. Psychological Bulletin 1994; 116:21-7.

35. Baños RM, Botella $C$, Alcañiz $M$, et al. Immersion and emotion: Their impact on the sense of presence CyberPsychology \& Behavior 2004; 7:734-41.

36. Baños RM, Botella C, Rubio I, et al. Presence and emotions in virtual environments: The influence of stereoscopy. CyberPsychology \& Behavior 2008; 11:1-8.

37. Baños RM, Liano V, Botella C, et al. Changing induced moods via virtual reality: Persuasive Lecture Notes In Computer Science 2006; 3962:7.

38. García-Palacios A, Baños RM. Eficacia de dos procedimientos de inducción del estado de ánimo e influencia de variables moduladoras. Revista de Psicopatología y Psicología Clínica 1999; 4:15-26.

39. Velten E. A laboratory task for induction of mood states. Behavior Research \& Therapy 1968; 6:473-82.

40. Lang PJ, Bradley MM, Cuthbert BN. (1995) International Affective Picture System (IAPS): Technical manual and affective ratings. NIMH Centre for the Study of Emotion and Attention, University of Florida.

41. Botella C, Etchemendy E, Castilla D, et al. An e-Health system for the elderly (Butler Project): A pilot study on acceptance and satisfaction. CyberPsychology \& Behavior 2009; 12:255-62.

42. Riva G, Mantovani F, Capideville CS, et al. Affective interactions using virtual reality: The link between presence and emotions. CyberPsychology \& Behavior 2007; 10:45-56.

43. Stetz M, Long C, Wiederhold BK, et al. Combat scenarios and relaxation training to harden medics against stress. Journal of CyberTherapy \& Rehabilitation 2008; 1:239-46.

44. Fredrickson B. The role of positive emotions in positive psychology. The broaden-and-build theory of positive emotions. American Psychologist 2001; 56:218-26.

45. Diener E, Suh EM, Lucas RE, et al. Subjective well-being: Three decades of progress. Psychological Bulletin 1999; 95:542-75.

46. Tellegen A, Lykken DT, Bouchard TJ, Jr, et al. Personality similarity in twins reared apart and together. Journal of Personality \& Social Psychology 1988; 54:1031-9.

47. Baños R, Garcia-Soriano G, Botella C, et al. (2009) Positive mood induction and well-being: HSI: 2nd Conference on Human System Interactions, pp. 514-16.
48. Fava GA, Tomba E. Increasing psychological well-being and resilience by psychotherapeutic methods. Journal of Personality 2009; 77:1903-34.

49. Ryff CD, Singer BH. Psychological well-being: Meaning, measurement, and implications for psychotherapy research. Psychotherapy \& Psychosomatics 1996; 65:14-23.

50. Ryff CD. Happiness is everything, or is it? Explorations on the meaning of psychological well-being. Journal of Personality \& Social Psychology, 1989; 57:1069-81.

51. Ryff CD, Singer B. The contours of positive human health. Psychological Inquiry 1998; 9:1-28.

52. Wiederhold BK, Wiederhold MD. Virtual reality for posttraumatic stress disorder and stress inoculation training. Journal of CyberTherapy \& Rehabilitation 2009; 1:23-35.

53. Hermans HJM, Kempen HJG, Van Loon R. The dialogical self: Beyond individualism and rationalism. American Psychologist 1992; 47:23-33.

54. Hermans HJM, Hermans-Konopka A. (2010) Dialogical self theory. Positioning and counter-positioning in a globalizing society. New York: Cambridge University Press.

55. Calefato C, Vernero F, Montanari R. (2009) Wikipedia as an example of positive technology: How to promote knowledge sharing and collaboration with a persuasive tutorial. 2nd Conference on Human System Interactions, pp. 510-16.

56. Lopez SJ. (2009) The future of positive psychology: Pursuing three big goals. In Snyder CR, Lopez SJ, eds. Oxford handbook of positive psychology. New York: Oxford University Press.

57. Fogg BJ. (2003) Persuasive technologies: Using computers to change what we think and do. San Francisco: Morgan Kaufmann.

58. Kanis M, Brinkman WP. (2008) Designing technologies that encourage the sharing of positive emotions. Emotion in HCI: Joint Proceedings of the 2005-2007. International Workshops, Stuttgart, Fraunhofer IRB Verlag.

59. Kanfer H, Goldstein AP. (1980) Helping people change: A Textbook of Methods. 2nd ed. New York: Pergamon Press.

60. Killingsworth MA, Gilbert DT. A wandering mind is an unhappy mind. Science 2010; 330:932.

61. Seligman MEP. (2011) Flourish: A new understanding of happiness and well-being — and how to achieve them. London: Nicholas Brealey.

62. Travis J. Science by the masses. Science 2008; 319:1750-2.

63. Gaggioli A, Riva G. Working the crowd. Science 2008; 321:5895.

64. Carr N. (2008) The big switch: Rewiring the world, from Edison to Google. New York: WW Norton.

65. Carr N. (2010) The shallows: What the Internet is doing to our brains. New York: WW Norton.

66. Snyder CR, Lopez SJ. (2009) Handbook of positive psychology. Cambridge, MA: Oxford University Press.

67. Amichai-Hamburger Y. (2009) Technology and psychological well-being. New York: Cambridge University Press.

Address correspondence to:

Dr. Cristina Botella Arbona

Departamento de Psicología Básica, Clínica y Psicobiología

Universitat Jaume I

Av. Vicente Sos Baynat s/n 12006 Castellón Spain

E-mail: botella@psb.uji.es 
Copyright of CyberPsychology, Behavior \& Social Networking is the property of Mary Ann Liebert, Inc. and its content may not be copied or emailed to multiple sites or posted to a listserv without the copyright holder's express written permission. However, users may print, download, or email articles for individual use. 